\title{
"You and your best friend Suzy put Slime in Ms. Smollett's desk": Producing false memories with self-relevant details
}

\author{
Tracy DesJardins ANd Alan Scoboria \\ University of Windsor, Windsor, Ontario, Canada
}

\begin{abstract}
Rates of false memory reports vary markedly in the published literature. In an effort to explain these differences, the present study investigated the effects of including different types of details in a false narrative upon subsequent false memory formation. Participants were assigned to one of four conditions in which the inclusion of self-relevant and/or specific details in a false event (putting a toy in a teacher's desk) was manipulated. Participants engaged in a standard memory recovery procedure over three interviews, involving recall for three true and one false event. Upon completion, $68.2 \%$ of participants in self-relevant groups were judged as having created memories or images about the false event, as compared with $36.4 \%$ in non-self-relevant groups. Subjective ratings of memory intensity were higher for self-relevant groups, and self-relevant participants were less likely to correctly guess the false event. These findings indicate that including self-relevant details in suggested childhood events increases the likelihood that such events will be accepted as false memories.
\end{abstract}

Interest in false memories continues to increase, in conjunction with advances in related areas of research and the widespread attention given to real life instances wherein memory accuracy has been questioned. Instead of exemplifying literal representations of original experience, it is now widely held that autobiographical memory is best conceptualized as a reconstructive process involving information from many sources (Schacter \& Addis, 2007). For example, the postevent contamination of memory is well documented (Loftus, 2003). In other research, the creation of false autobiographical memories has been investigated.

One empirical approach to memory falsification is the familial-informant false-narrative procedure (Lindsay, Hagan, Read, Wade, \& Garry, 2004). In this procedure, descriptions of childhood events are provided by participants' parents. Participants are then presented with true event descriptions and one event fabricated by researchers. Over several interviews, participants are encouraged to recall unremembered events, often using procedures that are purported to aid memory recovery, such as imagination. In a review of nine studies using these methods, Lindsay et al. calculated a mean false memory rate of $31 \%$. Recent studies (see below) have demonstrated even more dramatic rates.

Research has thus shown that false memory creation is a robust phenomenon. However, it remains unclear which factors drive their development. Numerous manipulations occur in these complex studies, and many variables operate within and between studies. Some factors have been investigated, such as event plausibility (Pezdek, Finger, \& Hodge, 1997) and the effects of imagination (Hyman \& Pentland, 1996). Other factors, such as social pressure or parental provision of information, are not as well understood. In the spirit of "dismantling" these complex studies (Scoboria, Mazzoni, Kirsch, \& Jimenez, 2006), the present study investigates one potentially relevant factor, the nature of details provided to participants within target false events.

Recent false memory studies have focused upon the media for presenting false events. Wade, Garry, Read, and Lindsay (2002) explored the potential for doctored photographs to foster false memories. After participants viewed a false photograph depicting them on a hot air balloon ride, $50 \%$ were judged as having developed some degree of memory. Subsequently, Lindsay et al. (2004) used standard narrative methodology to suggest a target event (getting in trouble at school), and provided half of the participants with a class picture from the grade when the event allegedly took place, to "aid in recall." When provided the photograph, an astonishing $72.8 \%$ of participants were judged to have created false memories $(65.2 \%)$ or images (13\%) associated with the false event, compared to $45.5 \%$ receiving the narrative alone.

Interested in exploring the apparent differences between narratives and photographs in fostering false memories, Garry and Wade (2005) studied their relative effects. Participants were informed about a fabricated hot air balloon ride in either narrative or photographic form. After three interviews, $50 \%$ of the photograph condition participants

A. Scoboria, scoboria@uwindsor.ca 
were judged as having generated false images or memories for the event, as contrasted with $82 \%$ of participants in the narrative condition. The authors explained the advantage for narratives in terms of fluency, suggesting that narratives provide free reign to confabulate event details, whereas photographs provide a specific set of details which limit one's ability to confabulate.

We suspect that another variable present in these studies may help explain the high false memory rates that are sometimes observed. Two studies reporting relatively high false memory rates have included self-relevant information in the false narratives provided by researchers. Lindsay et al.'s (2004) narrative incorporated the grade participants were in at the time of the event and their teachers' names. In Garry and Wade (2005), the narrative included the participants' hometowns and names of family members. Thus, we hypothesized that the provision of self-relevant information may elevate false memory rates. This view is supported by Hyman, Husband, and Billings's (1995) finding that participants whose imagery included self-knowledge were more likely to endorse false events as true. Hence, it may have been the unconstrained nature of narratives, differences in self-relevant information, or both that resulted in differences between narratives and photographs in Garry and Wade's study.

If false memory formation is indeed enhanced by selfrelevant narrative details, several mechanisms are likely involved. First, the preferential cognitive processing of self-relevant information is well documented. Research has demonstrated that self-schematic information is processed more rapidly than nonschematic information (Markus, 1977), and self-relevant memory encoding is superior to other forms of encoding (Rogers, Kuiper, \& Kirker, 1977). Superior recall for self-related information has been attributed to the self being a well developed, frequently used, and highly automatic knowledge construct (Symons \& Johnson, 1997). Thus, self-relevant information in narratives may carry greater weight than other details. Furthermore, recall of additional self-relevant information may be promoted via spreading activation, increasing "memory" for new details of false events.

Second, the fluency hypothesis (Bernstein, Whittlesea, \& Loftus, 2002; Jacoby, Kelly, \& Dywan, 1989) predicts that self-relevant details will influence false memory formation to the degree that they produce a sense of familiarity when they are encountered. The fluency experienced when encountering personal details may be misattributed to the unremembered event, which in turn may increase the likelihood of the event being accepted as true. This acceptance may then drive a desire to recall more details. It follows that fluency associated with self-relevant information may promote automatic and rapid "recognition" of an entire event as having occurred, upon which the false memory is subsequently elaborated.

According to either potential account, the presence of vivid, but not self-relevant, details should promote neither self-schematic activation nor fluency, as such details are not inherently familiar. Unusual details may even restrict memory formation, due to their lack of familiarity. This is similar to the constraint argument provided by Garry and
Wade (2005) for photographs: Specific visual details may constrain fluency. Thus, familiar details should facilitate false remembering, whereas unfamiliar or bizarre details should have little impact on (or may even decrease) its likelihood.

In the present study, we tested these assumptions by examining the influence of two types of narrative details upon false memory formation. Self-relevant details were highly unique to each individual participant. Specific details were vivid, non-self-relevant (but not bizarre) pieces of information, not central to the narrative. Using true events and self-relevant information provided by parents, we engaged participants in three interviews during which they were encouraged to recall three true events and one false event, before and after engaging in guided imagery. For the target event, the general script given to all participants involved getting in trouble at school and being punished. This narrative was augmented with self-relevant and/or specific details, resulting in four treatment groups (no details, specific details, self-relevant details, specific and self-relevant details).

We hypothesized that the inclusion of self-relevant details would inflate peoples' tendency to recall false events. Conversely, we anticipated that specific details would not uniquely facilitate (and might actually hinder) false recall. However, we expected participants who did not encounter self-relevant information would continue to exhibit a lesser degree of false memory formation, as prior research in which narratives without personalized information were suggested still resulted in some false memories.

\section{METHOD}

\section{Participants}

Forty-four University of Windsor undergraduate students ( 5 male, 39 female; age range 18-42 years, $M=22.5, S D=4.82$ ) completed the procedure. We originally approached 300 students not living with parents, who gave permission to contact their parents; 83 provided parental contact information. E-mail/mail responses were received for $68.6 \%$ of these students, $72 \%$ of whom completed all sessions. Participants received psychology course credit and entry into a raffle for $\$ 50$.

\section{Materials and Measures}

Contacting parents. Parents were contacted by mail or e-mail for information about true childhood events, experienced at or before the age of 6. They were given a list of event categories (e.g., hospital visit, getting lost, etc.) and were asked to describe the activities, location, people involved, and their child's age at the time. Parents also provided self-relevant information about their child, which was used to tailor false events for participants in self-relevant conditions (names of first-grade teachers; names of friends in class that year; favorite toys or objects their children had at the time). Parents were asked not to discuss the information provided with their children until the study had ended.

Manipulation. Participants were randomly assigned in advance of the first session to one of four conditions, using two factors (presence/absence of self-relevant or specific details): self-relevant and specific, self-relevant only, specific only, or no self-relevant or specific details. The false event, taken from Lindsay et al. (2004), involved getting into trouble and being punished in school. Events were personalized for participants by experimental condition (see the Appendix). The generic narrative consisted of a general script for the event, which was presented from the third-person perspective 
for consistency with Garry and Wade (2005) and other false memory studies (but differs from the parental, first-person perspective used by Lindsay et al.). The remaining conditions substituted self-relevant and/or specific information for general references to them in the script (e.g., "a friend," "a toy"). Self-relevant details included the name of each participant's first-grade teacher, the name of a friend in their class that year, and a favorite toy they had at the time. Specific details included the participant putting a "revolting slime" toy in the teacher's desk and having blamed a friend for making him/ her do it.

Three true events were selected from those provided by parents. These were written so that one roughly matched the false event in word count and detail, one contained more detail, and one contained less detail. Booklets containing the narratives were made for all participants.

ABMQ. Participants completed the Autobiographical Belief and Memory Questionnaire (ABMQ; Scoboria, Mazzoni, Kirsch, \& Relyea, 2004). On an 8-point scale, this questionnaire assesses general and personal plausibility (where $1=$ not at all plausible and $8=e x$ tremely plausible), autobiographical belief (where $1=$ definitely did not happen and $8=$ definitely did happen), and memory (where $1=$ no memory and $8=$ clear and complete memory). Participants were asked to provide these ratings for five events. The first, fourth, and fifth events were the same for all participants (choking, bone density screening, seeing a UFO). One of the participants' true events was placed second (to prevent the false event from standing out), and the false event was placed third. This was the first time participants were directly asked to rate their degrees of memory for the target events in this type of study.

Judges' ratings. On the basis of transcripts of Interviews 1 and 3 , participants were classified by two independent judges, blind to conditions, as having (1) no images, (2) images only, or (3) memories for each of the four events, according to Lindsay et al.'s (2004) criteria. Participants who reported actual memories were coded into the memory category; those who described images associated with the event, but not definitive memories, were classified in the images category. Judges initially concurred on $84 \%$ of cases; differences were resolved through discussion. The recall rate for true events was $87 \%$ across conditions.

Memory questions. Quality of memories for events was rated using questions described by Garry and Wade (2005). On a 7-point scale $(1=$ low and $7=$ high $)$, participants rated whether they could (1) relive the event in their mind; (2) see the event in their mind; (3) hear the event in their mind; (4) feel emotions associated with the event; (5) remember the event, rather than just know it happened; (6) remember the event as a coherent story; (7) believe the event occurred in the way remembered; and (8) remember talking/thinking about the event in the past.

\section{Procedure}

All procedures were approved by the University of Windsor psychology department ethics review committee. Participants meeting criteria were invited to provide parental contact information and were informed that parents would be contacted to obtain nonsensitive, childhood information. Upon receipt of parental reports, participants were contacted to set up the first interview. Participants completed three interviews over 1 week, according to Garry and Wade's (2005) procedure. In Interview 1, participants were told that the purpose of the study was to evaluate the effectiveness of memory recovery techniques for childhood events. They were told that their parents provided the event descriptions to be used in the study. The experimenter read aloud the four events in turn; the false event was presented third in the series. After each event, the participants were asked to describe everything they could remember about the event without leaving anything out. When an event was not remembered, participants were told that many people cannot recall events at first because they have not thought about them for a long time. Participants were then instructed to spend 1 min concentrating and trying to remember the event and were asked again what they could remember. Context reinstatement and guided imagery were then employed to encourage participants to imagine details. Specifically, they were asked to close their eyes, picture themselves in each situation, and think for $1 \mathrm{~min}$ about details such as what it might have been like, who was with them, and how they felt. Participants' oral recall was recorded during Interviews 1 and 3 for subsequent transcription and scoring.

Once unable to recall any more information about each event, participants completed the qualitative memory questionnaire. After the series of four events, participants were given a printed booklet containing their narratives, and were asked to review the book once daily to try to remember the events. Finally, participants were reminded not to discuss the study.

Interviews 2 and 3 followed the same procedures. After imagining each event, participants were asked to describe any details recalled. The memory questionnaire was not administered during Interview 2, nor were sessions recorded, consistent with prior research using this paradigm. After completing the memory questionnaire in Interview 3, participants completed the ABMQ. Next, they were asked how frequently they thought about events during the study and whether they had discussed the events with others. Participants were then told that one of the events was fabricated, and were asked to select which of the events they thought was false. Finally, the interviewer disclosed the false event, and participants were debriefed.

\section{RESULTS AND DISCUSSION}

Recall that the provision of self-relevant information was expected to bolster false memory formation. The findings supported this hypothesis: Including highly selfrelevant details in the description did increase the total number of images and memories associated with target events. The overall results are shown in Figure 1. Analysis of event classification (no images, images only, or memory) at Time 1 using logistic regression revealed that $65 \%$ of participants in self-relevant conditions generated images or memories, as compared with $40 \%$ in non-selfrelevant conditions $[B=1.13, S E=0.63$, Wald $=3.21$, $p=.073, \operatorname{Exp}(B)=3.09]$. By Time 3,68.2\% of participants in self-relevant conditions reported images or memories for the false event, but only $36.4 \%$ of participants in non-self-relevant conditions did so $[B=1.32, S E=$ 0.64 , Wald $=4.31, p<.05, \operatorname{Exp}(B)=3.76]$. No effect for specific details or interaction was observed at either time, although we note that the sample size may limit the power needed to observe any interaction effect $(p \mathrm{~s}>.10)$. Qualitative memory ratings did not reveal any significant group differences (all $p>.10$ ).

In false memory studies, the images-only category is equated with partial false memories (Lindsay et al., 2004). Most studies collapse across the images/partial memory and full memory categories to calculate false memory rates. By this criterion, false memory rates were judged to be higher in self-relevant groups. However, examining Figure 1, it appears that specific details increased rates of full memories in every condition. Exposure to selfrelevant and/or specific details resulted in identical full false memory rates, and neither factor statistically predicted full false memory rates (both n.s.). Self-relevant information thus facilitated partial false memories early in the process (at Time 1) that persisted across time, but these partial memories did not translate into a higher full false memory rate. Future research is necessary to deter- 


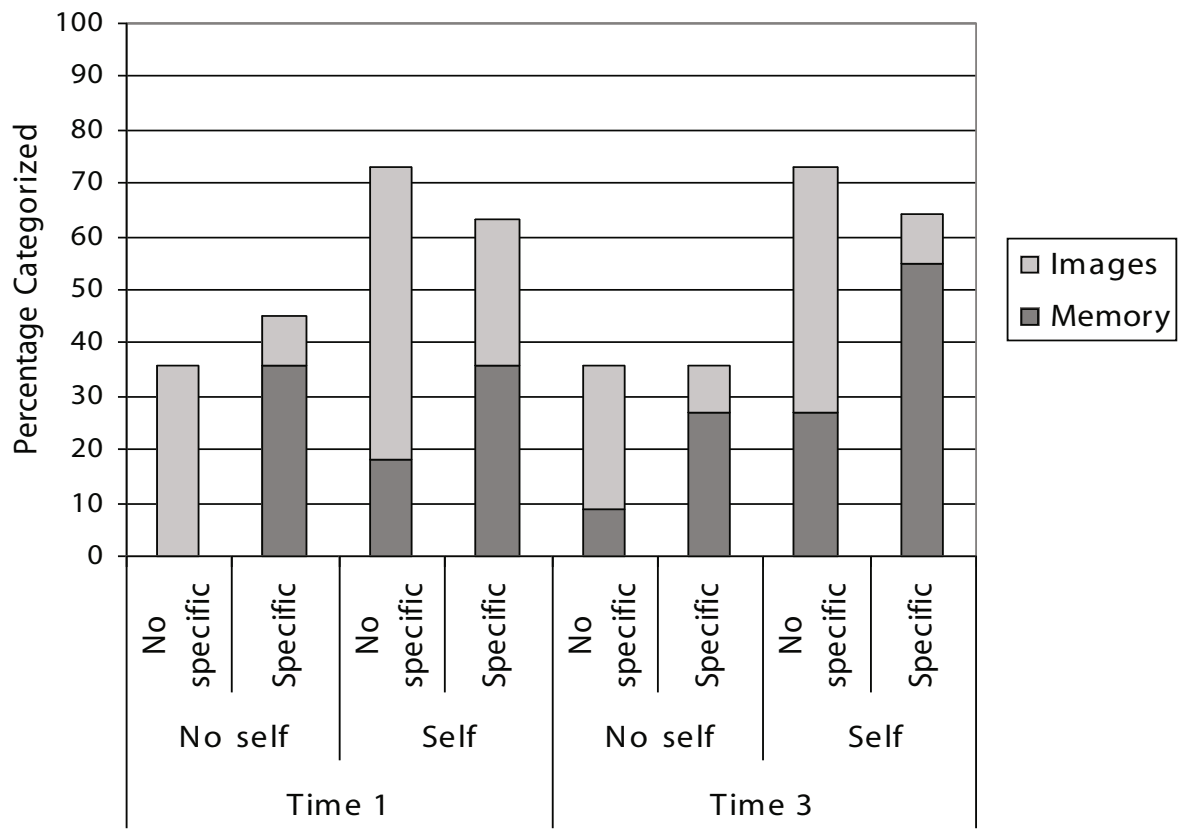

Figure 1. Percentages of participants reporting memories or images for the false event during Times 1 and 3, by experimental condition. There were 11 participants per condition. Specific, specific details; Self, self-relevant narrative details.

mine whether and under what conditions full false memories might develop from the higher number of partial memories in self-relevant conditions. It is also possible that "specific" details were occasionally self-relevant for some participants, leading to elevated false memories in the specific-detail group. Research that systematically varies the self-relevance of narrative details is necessary to address this potential confound.

Ratings by judges do not reflect participants' own sense of recall for events. Examination of participants' selfrated memory for target events indicated that self-relevant information promoted a subjective sense of recall. Average ABMQ memory ratings for participants exposed to self-relevant details were significantly greater than ratings for the non-self-relevant participants. A factorial betweensubjects ANOVA on the memory ratings (Table 1) after the third interview revealed a significant main effect for self-relevant detail $[F(1,43)=4.42, p<.05$, Cohen's $d=$ $0.69]$. The effects of specific details and the interaction were not significant $(p>.10)$. Groups did not differ on plausibility or belief ratings $(p>10)$. These results demonstrate the value of querying participants about the phenomenological nature of their false recollections. Inclusion of the ABMQ verified that judges' ratings mirrored participants' own sense of remembering.

ABMQ belief and memory ratings were compared for the nine self-relevant and four non-self-relevant participants judged as having full memories of the false event. Independent $t$ tests indicated trends for self-relevant participants to give higher ratings for both belief $[M=6.89$, $S D=1.23$ vs. $M=4.75, S D=2.5 ; t(11)=2.09, p=.06]$ and memory $[M=5.00, S D=1.94$ vs. $M=2.75, S D=$ $2.06 ; t(11)=1.89, p=.09]$. Both trends suggest that, for full false memories, self-relevance was associated with higher levels of belief and clarity of memory. However, these results were not statistically significant, presumably because of statistical power, and future corroboration is necessary.

Finally, we examined whether individuals in any group were less likely to guess correctly which of the events was false. Examination of frequencies indicated that participants exposed to self-relevant information were less likely to correctly identify the false narrative. Logistic regression demonstrated an effect for self-relevant information $[B=$ $-1.77, S E=0.87$, Wald $=4.12, p<.05, \operatorname{Exp}(B)=0.17]$; $36.4 \%$ of self-relevant participants, but only $9.1 \%$ of nonself-relevant participants, guessed incorrectly. No effect of specific detail or interaction emerged (all $p \mathrm{~s}>.10$ ). Thus, participants exposed to self-relevant information were more likely to erroneously name the false event as true, relative to participants not exposed to such information.

Table 1

Mean Autobiographical Belief and Memory Questionnaire Ratings for the False Event, by Experimental Condition

\begin{tabular}{|c|c|c|c|c|c|c|c|c|}
\hline & \multicolumn{2}{|c|}{$\begin{array}{c}\text { General } \\
\text { Plausibility }\end{array}$} & \multicolumn{2}{|c|}{$\begin{array}{c}\text { Personal } \\
\text { Plausibility }\end{array}$} & \multicolumn{2}{|c|}{$\begin{array}{c}\text { Autobiog. } \\
\text { Belief }\end{array}$} & \multicolumn{2}{|c|}{ Memory } \\
\hline & $M$ & $S D$ & $M$ & $S D$ & $M$ & $S D$ & $M$ & $S D$ \\
\hline \multicolumn{9}{|l|}{ No self } \\
\hline No specific & 4.55 & 2.07 & 5.36 & 1.63 & 4.00 & 1.26 & 1.64 & 1.2 \\
\hline Specific & 4.82 & 1.78 & 4.73 & 2.28 & 3.55 & 1.75 & 1.27 & 0.91 \\
\hline \multicolumn{9}{|l|}{ Self } \\
\hline No sp & 4.5 & 1.3 & 4.1 & 2.48 & 3.36 & 2.66 & 2.45 & 2.5 \\
\hline Specific & 4.55 & 1.81 & 5.36 & 2.29 & 5.18 & 2.48 & 2.82 & 2.2 \\
\hline
\end{tabular}

Note-Self, self-relevant narrative details; Specific, specific narrative details. 
The present findings provide a potential explanation for inconsistencies in false memory rates in prior research. As noted previously, studies that have found higher false memory rates have also included some personalized information in narratives provided to participants. In fact, our present images plus memories rate of $68.2 \%$ is quite similar to the average rate of $69.4 \%$ in the combined narrative conditions from Lindsay et al. (2004) and Garry and Wade (2005). This finding contrasts with studies that did not provide self-relevant information, which Lindsay et al. estimate to have an average false memory rate of $31 \%$, similar to our rate of $36.4 \%$ using non-self-relevant narratives.

Taken together, these findings support the importance of self-related processes in false memory formation. The inclusion of self-relevant information was associated with rapid development of memory-like images, as assessed by judges and subjective reports of enhanced clarity of recall. Furthermore, self-relevant details interfered with the ability to correctly identify the false event. These findings suggest that self-relevant information serves a prominent role in determining whether something occurred in the past, and appear to support the fluency-based account of remembering. Participants in the self-relevant groups are theorized to have experienced aspects of the narrative as highly familiar. Accordingly, this familiarity may have facilitated ease of remembering (Jacoby, Kelly, \& Dywan, 1989), which in turn promoted a tendency for participants to implicitly accept the entire event as true. The event is accepted as being "about myself," and then one simply must fill in the missing details.

The trends toward higher ABMQ belief and memory ratings for self-relevant events that were classified as memories suggest that self-relevant information may result in false memories that are held with greater conviction. Subjective intensity of memory is not typically studied; however, this factor is important when trying to understand what influences the formation of false memories that are held with conviction. These results also demonstrate the value of querying study participants directly about their recollection for target events.

The specific, non-self-relevant details we employed did not impact false memories. These details were not particularly unusual, and thus may not have contributed to outcomes. Further research could incorporate other types of details, including those that are bizarre, to determine whether certain details can negatively impact false memory rates. It is also interesting to speculate at what point self-relevant information might cease to foster, and instead begin to impede, false memories. For example, future research could examine effects of providing large amounts of self-relevant information, or providing selfrelevant information in incorrect narrative contexts.

Several practical implications emerge from the present findings. They suggest that false memories may be fostered by incorporating self-relevant details into the therapeutic or legal process. For example, Lindsay et al. (2004) note that certain therapeutic approaches advise viewing family photo albums, with the intent of triggering memories of abuse. The present results suggest that self-relevant details contained therein may activate self- schematic processes, facilitating the construction of false memories. When combined with other suggestive practices, inaccurate judgments about past abuse appear all too likely. The findings also suggest that oral presentation of idiosyncratic information is sufficient to foster this process. Naturally, the importance of self-relevant details in photographs must be confirmed by work in that medium.

We note that, although the present study (and several others) indicate that some recovered memories are untrue, other research shows that recovered memories are sometimes partly or mostly accurate, reflecting genuine memories of past events (see Schooler, 1999). The point of false memory research is not to argue that recovered memories are always false, but to better understand the parameters under which inaccurate memories may arise. Also, despite researchers' intentions to employ improbable false events, there remains some possibility that target events (or similar events) actually occurred to any given participant.

We conducted the present study to add to the current body of research exploring the factors that may contribute to false memory formation. Although it is well documented that false memories can be created in the laboratory, the contributing mechanisms are not entirely clear. Self-related cognitive processes are key factors that should receive consideration in future false memory implantation studies. These findings suggest that individuals are easily deceived by the sense of an event being self-related, and therefore accept that it must have occurred in its entirety.

\section{AUTHOR NOTE}

The data were collected in partial completion of the first author's honors B.A. at the University of Windsor; she is now at the University of Victoria. We thank Marc Frey, Norm Lundale, and Maria Soubboutina for their assistance in judging memory reports. We also extend gratitude to Maryanne Garry, Stephen D. Goldinger, and two anonymous reviewers for comments that improved the manuscript. Correspondence related to this article may be sent to A. Scoboria, Department of Psychology, 401 Sunset Avenue, Windsor, ON, N8Y 3E5 Canada (e-mail: scoboria@uwindsor.ca).

\section{REFERENCES}

Bernstein, D. M., Whittlesea, B. W. A., \& Loftus, E. F. (2002). Increasing confidence in remote autobiographical memory and general knowledge: Extensions of the revelation effect. Memory \& Cognition, 30, 432-438.

GARRY, M., \& WADE, K. (2005). Actually, a picture is worth less than 45 words: Narratives produce more false memories than photographs do. Psychonomic Bulletin \& Review, 12, 359-366.

Hyman, I. E., Husband, T. H., \& Billings, F. J. (1995). False memories of childhood experiences. Applied Cognitive Psychology, 9, 181197.

Hyman, I. E., \& Pentland, J. (1996). The role of mental imagery in the creation of false childhood memories. Journal of Memory \& Language, 35, 101-117.

Jacoby, L. L., Kelley, C. M., \& Dywan, J. (1989). Memory attributions. In H. L. Roediger III \& F. I. M. Craik (Eds.), Varieties of memory and consciousness: Essays in honour of Endel Tulving (pp. 391-422). Hillsdale, NJ: Erlbaum.

Lindsay, D. S., Hagen, L., Read, J. D., Wade, K. A., \& Garry, M. (2004). True photographs and false memories. Psychological Science, 15, 149-154.

LofTus, E. F. (2003). Make-believe memories. American Psychologist, 58, 867-873.

Markus, H. (1977). Self-schemata and processing information about the self. Journal of Personality \& Social Psychology, 35, 63-78.

Pezdek, K., Finger, K., \& Hodge, D. (1997). Planting false childhood 
memories: The role of event plausibility. Psychological Science, $\mathbf{8}$, 437-441.

Rogers, T. B., KuiPer, N. A., \& Kirker W. S. (1977). Self-reference and the encoding of personal information. Journal of Personality \& Social Psychology, 35, 677-688.

Schacter, D. L., \& AdDis, D. R. (2007). Constructive memory: The ghosts of past and future. Nature, 445, 27.

Schooler, J. (1999). Discovered memories and the "delayed discovery" doctrine: A cognitive case-based analysis. In S. Taub (Ed.), Recovered memories of child sexual abuse: Psychological, social, and legal perspectives on a contemporary mental health controversy (pp. 121-141). Springfield, IL: Charles C. Thomas.
Scoboria, A., Mazzoni, G., Kirsch, I., \& Jimenez, S. (2006). The effects of prevalence and script information on plausibility, belief, and memory of autobiographical events. Applied Cognitive Psychology, 20, 1049-1064.

Scoboria, A., Mazzoni, G., Kirsch, I., \& Relyea, M. (2004). Plausibility and belief in autobiographical memory. Applied Cognitive Psychology, 18, 791-807.

Symons, C. S., \& Johnson, B. T. (1997). The self-reference effect in memory: A meta-analysis. Psychological Bulletin, 121, 371-394.

Wade, K. A., Garry, M., Read, J. D., \& Lindsay, D. S. (2002). A picture is worth a thousand lies: Using false photographs to create false childhood memories. Psychonomic Bulletin \& Review, 9, 597-603.

\section{APPENDIX \\ Narrative Descriptions Used in Experimental Conditions}

Items in italics below indicate specific details; items in bold indicate self-relevant details.

\section{No Specific, No Self-Relevant Narrative Details}

When you were in grade 1, you had a toy that many kids used to play with. You took it to school and put it somewhere that you shouldn't have with one of your friends. Your teacher wasn't very happy and punished you by taking something away from you for the rest of the day.

\section{Specific, No Self-Relevant Narrative Details}

When you were in grade 1, you had one of those revolting Slime toys that many kids used to play with. You took it to school and slid it into your teacher's desk when they weren't looking, and then blamed your friend for making you do it. Your teacher wasn't very happy and punished you by taking something away from you for the rest of the day.

\section{No Specific, Self-Relevant Narrative Details}

When you were in grade 1, you had a toy that many kids used to play with. You took it to school and put it somewhere that you shouldn't have with your friend, [friend's name]. Your teacher, [teacher's name], wasn't very happy and punished you by taking away your [name of favorite toy/object] for the rest of the day.

\section{Specific, Self-Relevant Narrative Details}

When you were in grade 1, you had one of those revolting Slime toys that many kids used to play with. You took it to school and slid it into your teacher's desk when he/she wasn't looking, and then blamed your friend, [friend's name], for making you do it. Your teacher, [teacher's name], wasn't very happy and punished you by taking away your [name of favorite toy/object] for the rest of the day.

(Manuscript received October 27, 2006;

revision accepted for publication March 20, 2007.) 